\title{
An RND transporter in the monoterpene metabolism of Castellaniella defragrans
}

\author{
Edinson Puentes-Cala $(\mathbb{D} \cdot$ Jens Harder
}

Received: 15 May 2018/Accepted: 27 September 2018/Published online: 17 October 2018

(C) The Author(s) 2018

\begin{abstract}
The betaproteobacterium Castellaniella defragrans 65Phen grows on monoterpenes at concentrations toxic to many bacteria. Tolerance mechanisms include modifications of the membrane fatty acid composition and the mineralization of monoterpenes. In this study, we characterized an efflux transporter associated to the monoterpene metabolism. The inner-membrane transporter AmeD (apolar monoterpene efflux) affiliated to the HAE3 (hydrophobe/amphiphile efflux) family within the Resistance-Nodulation-Division (RND) superfamily. RND pumps of the HAE3 family are known for transporting substrates into the periplasm. AmeD is co-expressed with the outer membrane protein AmeA and the periplasmic proteins $\mathrm{AmeB}$ and $\mathrm{AmeC}$, suggesting an export channel into the environment similar to HAE1type RND exporters. Proteins AmeABCD are encoded within a genetic island involved in the metabolism of acyclic and cyclic monoterpenes. The deletion of ame $A B C D$ translated into a decrease in tolerance to monoterpenes in liquid cultures. The addition of
\end{abstract}

Electronic supplementary material The online version of this article (https://doi.org/10.1007/s10532-018-9857-6) contains supplementary material, which is available to authorized users.

E. Puentes-Cala $(\bowtie) \cdot$ J. Harder

Dept. of Microbiology, Max Planck-Institute for Marine

Microbiology, Celsiusstr. 1, 28359 Bremen, Germany

e-mail: epuentes@mpi-bremen.de;

epuentes@corrosion.uis.edu.co acetate as cosubstrate in limonene-containing cultures partially alleviated monoterpene toxicity in the deletion mutant. Accumulation of Nile Red in cells of $C$. defragrans required dissipation of the proton motive force with carbonyl cyanide $m$-chlorophenylhydrazone (CCCP). Cells lacking AmeABCD accumulated more Nile Red, suggesting an export function of the proteins. Our observations suggest that the tetrapartite RND transporter AmeABCD acts as an exporter during monoterpene detoxification in $C$. defragrans.

Keywords RND efflux pump - Monoterpene · Toxicity $\cdot$ Anaerobic metabolism $\cdot$ Castellaniella defragrans

\section{Introduction}

Monoterpenes are a diverse group of volatile biogenic hydrocarbons found mainly in the essential oils of plants. Produced as secondary metabolites, these compounds exhibit a myriad of biological functions such as pollinator attraction, plant-plant communication and as antimicrobials (Mahmoud and Croteau 2002). Due to their hydrophobic nature, monoterpenes tend to accumulate in cellular membranes altering the proton gradient, the electron transport and the stability of membrane proteins (Abrahim et al. 2003; Brennan et al. 2012; Griffin et al. 1999). Microorganisms using 
monoterpenes as carbon and energy sources have evolved mechanisms to circumvent this toxicity. Changes in membrane fluidity, monoterpene biotransformation and active secretion count among such adaptations (Bicas et al. 2008; Ramos et al. 2002; Ultee et al. 2000). Several efflux pumps of the Resistance-Nodulation-Division (RND) superfamily are reported to confer tolerance towards monoterpenes and other hydrocarbons (Kieboom et al. 1998; Segura et al. 2012). The RND efflux transporters MexABOprM and MexCD-OprJ have shown to be essential for growth of Pseudomonas aeruginosa exposed to monoterpene constituents of the tea-tree oil ( $\mathrm{Pa}$ padopoulos et al. 2008). Similarly, the complex AcrAB-TolC and several mutants thereof increased tolerance and enhanced monoterpene production in engineered E. coli strains (Dunlop et al. 2011; Foo and Leong 2013). Typically, RND efflux transporters active on volatile hydrocarbons belong to the hydrophobe/amphiphile efflux-1 (HAE1) family (Eswaran et al. 2004; Garcia et al. 2010; Nikaido 2011; Tseng et al. 1999). Members of this family are mostly tripartite consisting of an inner membrane substrate/ proton antiporter, an outer membrane pore and a periplasmic membrane fusion protein (MFP). The latter links the inner and outer membrane components and facilitates substrate transport across the periplasm straight into the extracellular environment. Substrate specificity is determined by the inner membrane RND pump which recruits substrates from the periplasm or from the outer leaflet of the inner membrane (Daury et al. 2016; Nikaido 2011).

The betaproteobacterium Castellaniella (ex Alcaligenes) defragrans 65Phen mineralizes several monoterpenes under denitrifying conditions (Foss et al. 1998) and tolerates concentrations of $\alpha$-phellandrene up to $30 \% \mathrm{v} / \mathrm{v}$ in a two-phase system (Heyen 1999). The proteome of $C$. defragrans grown on $\alpha-$ phellandrene revealed the increased expression of the putative RND transporter AmeD, as well as AmeABC, whose genes (ame $A B C)$ are encoded directly upstream of ameD (Petasch et al. 2014). In the same study, a transposon insertion in ameB resulted in defective growth on several monoterpenes. The gene cassette ame $A B C D$ is co-located with several genes associated to the monoterpene metabolism (Fig. 1). In this study, we characterized the AmeABCD system conducting transport and growth studies with $C$. defragrans
65Phen and a deletion mutant lacking the genes ameABCD.

\section{Materials and methods}

Bacterial strains and culture conditions

An in-frame deletion mutant lacking the gene cassette ame $A B C D$ ( $C$. defragrans 65Phen $\triangle a m e A B C D)$ was prepared from $C$. defragrans $65 \mathrm{Phen} \mathrm{Rif}^{\mathrm{R}}$ as previously described (Lüddeke et al. 2012), and kindly provided by Jan Petasch (Max Planck Institute for Marine Microbiology, Bremen). C. defragrans 65Phen $\mathrm{Rif}^{\mathrm{R}}$ is referred to in the text as the wild-type strain. The construct for ameABCD deletion was prepared using the primer pairs Ameup_XbaI_F (ATCGATCTAGAT GGCGCGAGGTGGTGTTGTC) and Ameup_SpeI_R (CCGACGACTAGTGGCAAGACCCGCAACCTGTG), and Amedown_SpeI_F (AAGCTAACTAGTCATGTG TGTCTCCTCTGTGGTT) and Amedown_HindIII_R (ACTCAAAGCTTCTACTGAAAAACAGGAACG CAG). The deletion mutant and the rifampicinresistant $C$. defragrans 65Phen (in the text referred to as wild-type) were cultivated in liquid artificial fresh water (AFW) medium under anoxic denitrifying conditions as described elsewhere (Petasch et al. 2014). When indicated 10 or $20 \mathrm{mM}$ of sodium acetate were added as carbon source. Monoterpenes ( $>90 \%$ purity, SigmaAldrich, Germany) were supplied either in the carrier phase 2,2,4,4,6,8,8-heptamethylnonane (HMN) or dissolved in dimethyl sulfoxide (DMSO). Cultures were incubated at $28{ }^{\circ} \mathrm{C}$ under constant agitation (60 rpm). Microbial growth was monitored by measuring the optical density at $600 \mathrm{~nm}$.

\section{Fluorometric assays}

As a proof of concept, Nile Red accumulation and extrusion was tested in $C$. defragrans cells by modifying previously described protocols (Bohnert et al. 2010, 2011). Briefly, cells of wild-type $C$. defragrans and $\triangle a m e A B C D$ were grown to late exponential phase in AFW medium containing both limonene ( $3 \mathrm{mM}$ in HMN) and acetate $(10 \mathrm{mM})$ as carbon sources. Cells of both strains grown only on acetate $(10 \mathrm{mM})$ were also tested. The cells were harvested at $5000 \times g$ for $30 \mathrm{~min}$ at $20^{\circ} \mathrm{C}$ and washed two times with AFW medium without any organic carbon source. After 


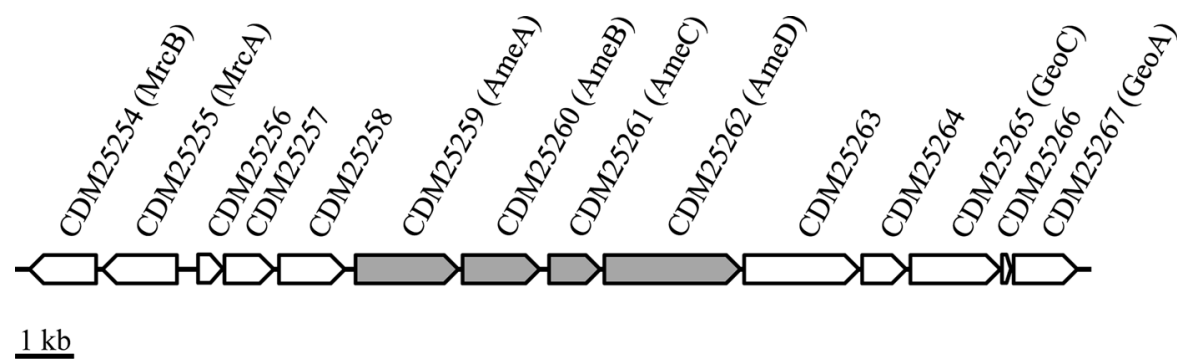

Fig. 1 Gene cluster of the putative RND transporter $\mathrm{AmeABCD}$ (grey) and its genetic neighbors within the genomic island specialized in monoterpene metabolism: upstream the

centrifugation, cells were resuspended in the same carbon-deprived medium to $\mathrm{OD}_{600} 0.5$ and, when indicated, carbonyl cyanide $m$-chlorophenylhydrazone (CCCP) and phe-arg $\beta$-naphthylamide (PA $\beta N)$ were added to final concentrations of $2 \mu \mathrm{M}$ and $20 \mu \mathrm{g} \mathrm{mL}^{-1}(38.5 \mu \mathrm{M})$, respectively (from stock solutions of $200 \mu \mathrm{M}$ CCCP and $2 \mathrm{mM} \mathrm{PA \beta N}$ in DMSO). The handling and preparation of microbial suspensions and chemical solutions was performed in an anaerobic chamber at $4{ }^{\circ} \mathrm{C}$. For influx assays, $198 \mu \mathrm{L}$ of each cell suspension was transferred to a black 96-well plate (Fluotrac, Greiner Bio-One $\mathrm{GmbH}$, Frickenhausen, Germany). Fifteen minutes after CCCP addition, Nile Red was added to a concentration of $2 \mu \mathrm{M}$ (from a $200 \mu \mathrm{M}$ stock solution in DMSO) and homogenized by repeated pipetting. The plate was covered with a sealing-film (thickness $50 \mu \mathrm{m}$, Carl Roth $\mathrm{GmbH}$, Karlsruhe, Germany) to minimize exposition to oxygen during fluorescence monitoring. Fluorescence intensity was measured at room temperature with an Infinite M200 PRO (Tecan Austria GmbH, Grödig, Austria) with excitation at $552 \mathrm{~nm}$ and emission at $636 \mathrm{~nm}$. Prior to each measurement, the plate was automatically shaken at $691 \mathrm{rpm}$ for $30 \mathrm{~s}$ at an amplitude of $1.5 \mathrm{~mm}$. To measure the efflux of Nile Red, cells were incubated anaerobically under constant shaking $(60 \mathrm{rpm})$ with $2 \mu \mathrm{M}$ of Nile Red and $2 \mu \mathrm{M}$ of CCCP for $2 \mathrm{~h}$ at room temperature. Cells were washed two times by centrifugation at $5000 \times g$ for $15 \mathrm{~min}$ at $20^{\circ} \mathrm{C}$ and resuspended in AFW medium deprived of carbon sources. When indicated, PA $\beta \mathrm{N}(38.5 \mu \mathrm{M})$ was added to cell suspensions. $190 \mu \mathrm{L}$ of the cell suspension were transferred to a 96-well plate and reenergized with $50 \mathrm{mM}$ of sodium acetate. The plate was covered with monoterpene ring cleavage operon $\operatorname{mrcABCDEFGH}$ and downstream parts of the cyclic monoterpene metabolism ( $\mathrm{geoA}$ and $g e o C$ )

sealing film, rapidly taken out of the anaerobic chamber and fluorescence was measured.

Bioinformatics analysis

NCBI, UniProt and RAST (Overbeek et al. 2014) were used to retrieve protein sequences for AmeABCD and related proteins, and to perform similarity and identity searches (Altschul et al. 1990), and conserved domain architecture analysis (Marchler-Bauer et al. 2017). AmeABCD sequences were analyzed for signal peptides, transmembrane helices and subcellular localization prediction using SignalP v4.1 (Nielsen 2017), TMHHM v2.0 (Krogh et al. 2001) and PSORTb v3.0.2 (Yu et al. 2010), respectively. The results obtained were validated by comparison with the results from InterPro (Finn et al. 2017). Visualization of transmembrane regions was generated with TMRPres2D (Spyropoulos et al. 2004). Three dimensional protein modeling was conducted with Phyre2 (Kelley et al. 2015). For the phylogenetic analysis of AmeD, sequences from the RND families HAE1, HAE2 and HAE3 were extracted from the TCDB database (Saier et al. 2016) and aligned with MAFFT v7.0 (Katoh et al. 2017). A maximum likelihood tree based on the JTT matrix model was calculated using MEGA v7.0 (Kumar et al. 2016) performing 1000 bootstrap replicates. Gene cassettes homologous to ame $A B C D$ in composition and organization were identified and selected from RAST (Overbeek et al. 2014), UniProt and NCBI databases. Homologous proteins from each cassette were clustered and aligned. The alignments were concatenated into a consensus alignment and used for inferring a maximum likelihood tree. The trees were visualized with Archaeopteryx v0.9921 beta (Han and Zmasek 2009). 


\section{Results and discussion}

Growth on monoterpenes

The transposon insertion mutant $C$. defragrans $65 \mathrm{Phen}$ ameB::Tn5 revealed reduced growth on several monoterpenes (Petasch et al. 2014). To assess the role of the putative RND transporter during monoterpene utilization, the wild-type strain and the deletion mutant 65Phen $\triangle a m e A B C D$ were compared in growth experiments (Fig. 2). Both strains exhibited similar growth when fed with acetate as sole carbon source (Fig. 2a) as well as with the monoterpenoids perillyl alcohol, perillyl aldehyde and perillic acid (Figs. 2b, $\mathrm{S} 1 \mathrm{a}, \mathrm{b})$. The physiological consequences of ame $A B C D$ deletion were observed during growth on limonene, $\alpha$ terpinene and other non-functionalized monoterpenes as sole carbon and energy sources (Figs. 2c, S1c-f). In
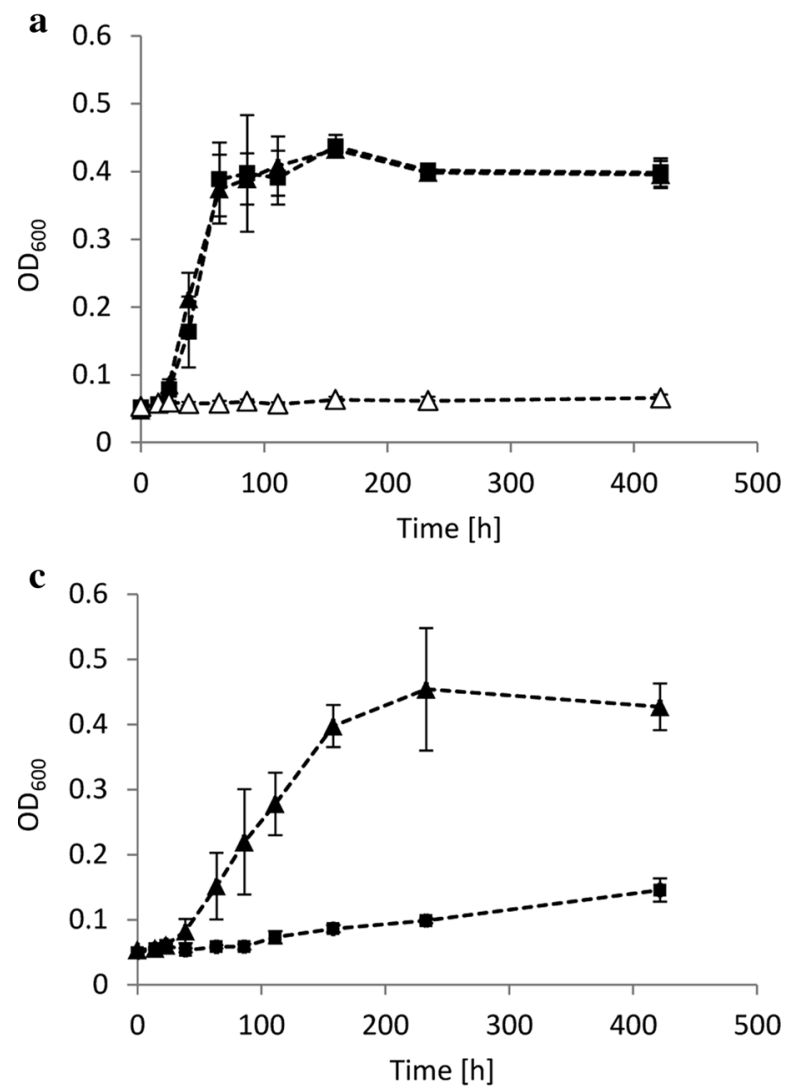

Fig. 2 Bacterial growth of wild-type (filled triangles) and $\triangle a m e A B C D$ (filled squares) strains of $C$. defragrans 65Phen on acetate (a), perillyl alcohol (b), limonene (c), and acetate and limonene (d) monitored at $\mathrm{OD}_{600}$. No increase in optical density these cultures, the deletion mutant grew only poorly in comparison to wild-type cells, suggesting a reduced tolerance towards non-functionalized monoterpene hydrocarbons. This apparent cytotoxicity is usually the result of monoterpene accumulation in cellular membranes, which affects membrane stability, impairs the maintenance of a proton gradient and hinders energy conservation (Segura et al. 2012; Sikkema et al. 1995). Remarkably, the deleterious effects of limonene on the growth of the deletion mutant were overcome when acetate and limonene were both added to the culture medium (Fig. 2d).

To further characterize this latter finding, the carrier phase HMN was replaced by DMSO. DMSO facilitated limonene dissolution in the medium and allowed to test higher monoterpene concentrations, while acetate was kept constant $(10 \mathrm{mM})$. Here, the deletion mutant strain showed growth comparable to the wild-
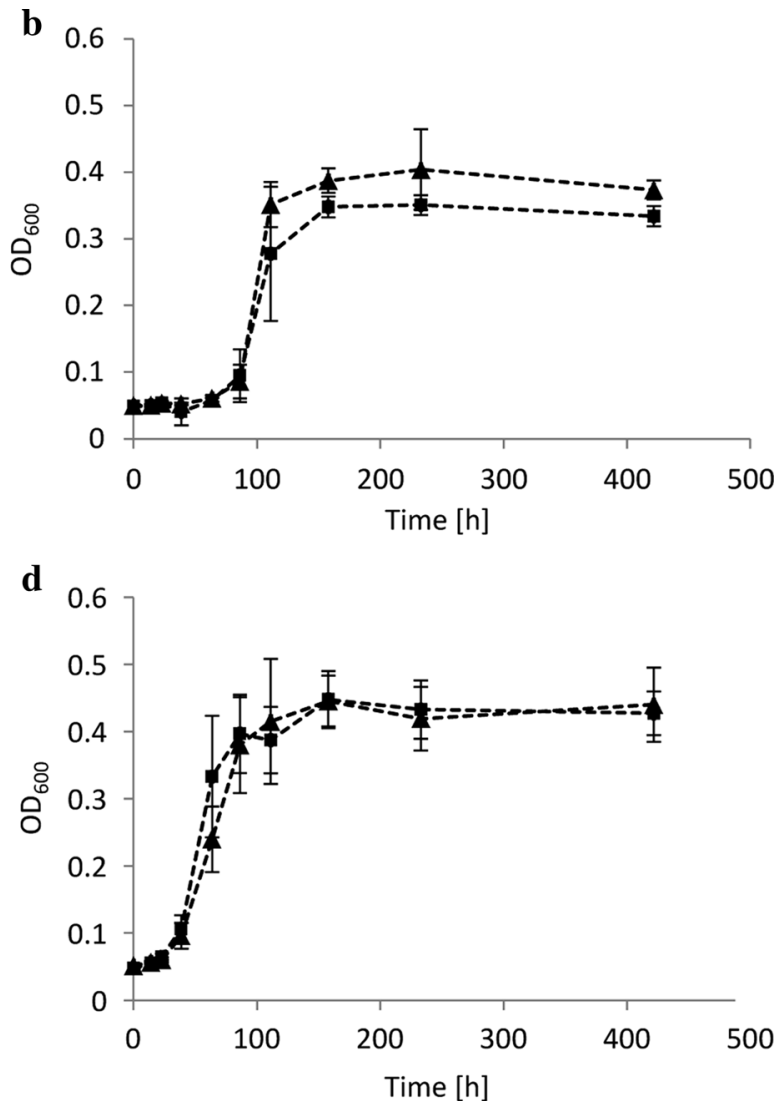

was observed in cultures deprived of a carbon source (open triangles). Monoterpenes and acetate were added at concentrations of 3 and $10 \mathrm{mM}$, respectively. The error bars correspond to the standard deviation of at least three independent experiments 
type when limonene was added to concentrations up to $5 \mathrm{mM}$ (Figs. 3, S2). The addition of higher limonene concentrations, however, reduced significantly the growth of $\triangle a m e A B C D$ cells. These observations suggest that the addition of acetate as cometabolic substrate translates into a significant increase in monoterpene tolerance. It is likely that, as observed in the past, the energy derived from acetate oxidation is used to fuel cellular detoxification mechanisms (Abrahim et al. 2003; Segura et al. 2012; Sikkema et al. 1995; Uribe et al. 1984). Unlike the mutant $\triangle a m e A B C D$, the wild-type strain showed growth in all limonene concentrations tested (Figs. 3, S2), suggesting that proteins AmeABCD are essential for growth under high monoterpene concentrations and may constitute a defense mechanism against monoterpene toxicity in C. defragrans. AmeABCD may supplement other monoterpene tolerance mechanisms known in $C$. defragrans such as adaptational changes in membrane composition and biotransformation of monoterpene substrates (Foss and Harder 1998; Harder and Marmulla 2017).

Influx and efflux of Nile Red

A set of fluorometric assays were conducted to monitor the in vivo accumulation and export of Nile Red in $C$. defragrans wild-type and $\triangle a m e A B C D$. The

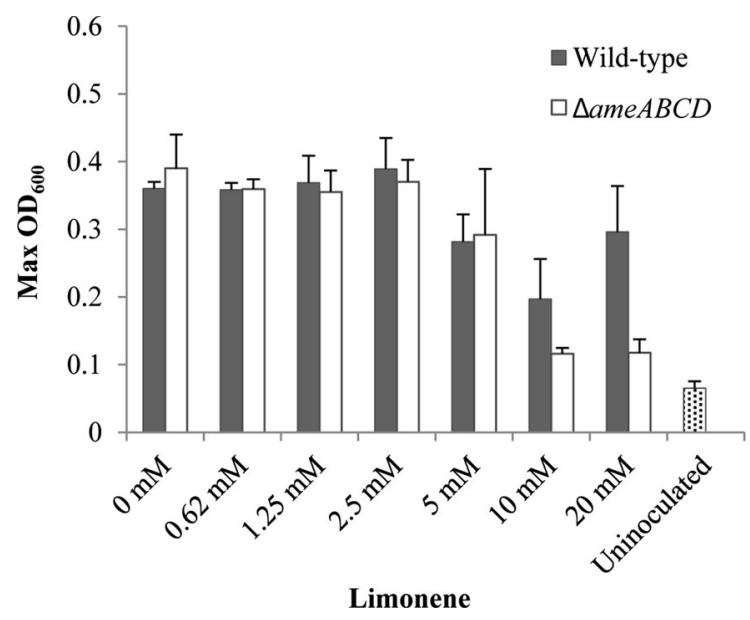

Fig. 3 Maximum optical densities of wild-type and $\triangle$ ame $A B C D C$. defragrans 65 Phen in acetate $(10 \mathrm{mM})$ cultures containing limonene at various concentrations. Limonene was dissolved in DMSO prior to addition to the medium to facilitate mass transfer. The error bars indicate the standard deviation of the means for three independent experiments cells were grown in AFW medium with $10 \mathrm{mM}$ acetate as only carbon source and in cometabolism with $3 \mathrm{mM}$ limonene dissolved in HMN. Given its lipophilic nature, Nile Red accumulates in cell membranes which results in a significant increase in its fluorescent quantum yield (Blair and Piddock 2016). Assays with Nile Red and other environment-sensitive dyes are routinely used as proxy to show the contribution of efflux pumps in bacterial resistance to xenobiotics (Blair and Piddock 2016; Paulsen et al. 1996; Soto 2013). In our experiments Nile Red accumulated in $C$. defragrans cells treated with the protonophore carbonyl cyanide $m$-chlorophenyl hydrazine (CCCP), but not in untreated cells (Fig. 4). The lack of fluorescence signal in the untreated controls (Fig. 4a) indicates that Nile Red is a suitable substrate for proton-driven efflux pumps present in physiologically active cells of both the wildtype and the $\triangle a m e A B C D$ strains. When de-energized with $\mathrm{CCCP}$, the mutant $\triangle a m e A B C D$ exhibited a slightly higher Nile Red accumulation than the wildtype (Fig. 4b), suggesting a contribution of AmeABCD to a residual export of Nile Red in the wild-type strain even in the presence of the protonophore. The addition of the RND transporter inhibitor phenylalanine-arginine $\beta$-naphthylamide $(\mathrm{PA} \beta \mathrm{N})$ increased the accumulation of Nile Red in the wild-type strain and thus confirmed that the residual export activity was caused by still active RND efflux pumps (Fig. 4c). Interestingly, when both strains were grown on acetate as only carbon and energy source, they once more accumulated similar amounts of Nile Red (Fig. 4d). The latter coincides with previous observations which showed that the expression of genes ame $A B C D$ in $C$. defragrans is triggered by exposure to monoterpenes, but not detectable when cells are grown on acetate only (Petasch et al. 2014).

Real-time efflux experiments typically require the re-energization of CCCP-treated cells loaded with Nile Red using a readily fermentable substrate such as glucose (Bohnert et al. 2010; Paixao et al. 2009). In non-fermenting bacteria such as $C$. defragrans dye efflux is generally inferred from measuring intracellular dye accumulation rather than from online efflux measurements (Morita et al. 2001; Richmond et al. 2013). Nevertheless, as a proof of concept a real-time Nile Red efflux assay was conducted with Nile Redpreloaded $C$. defragrans wild-type and $\triangle a m e A B C D$. 

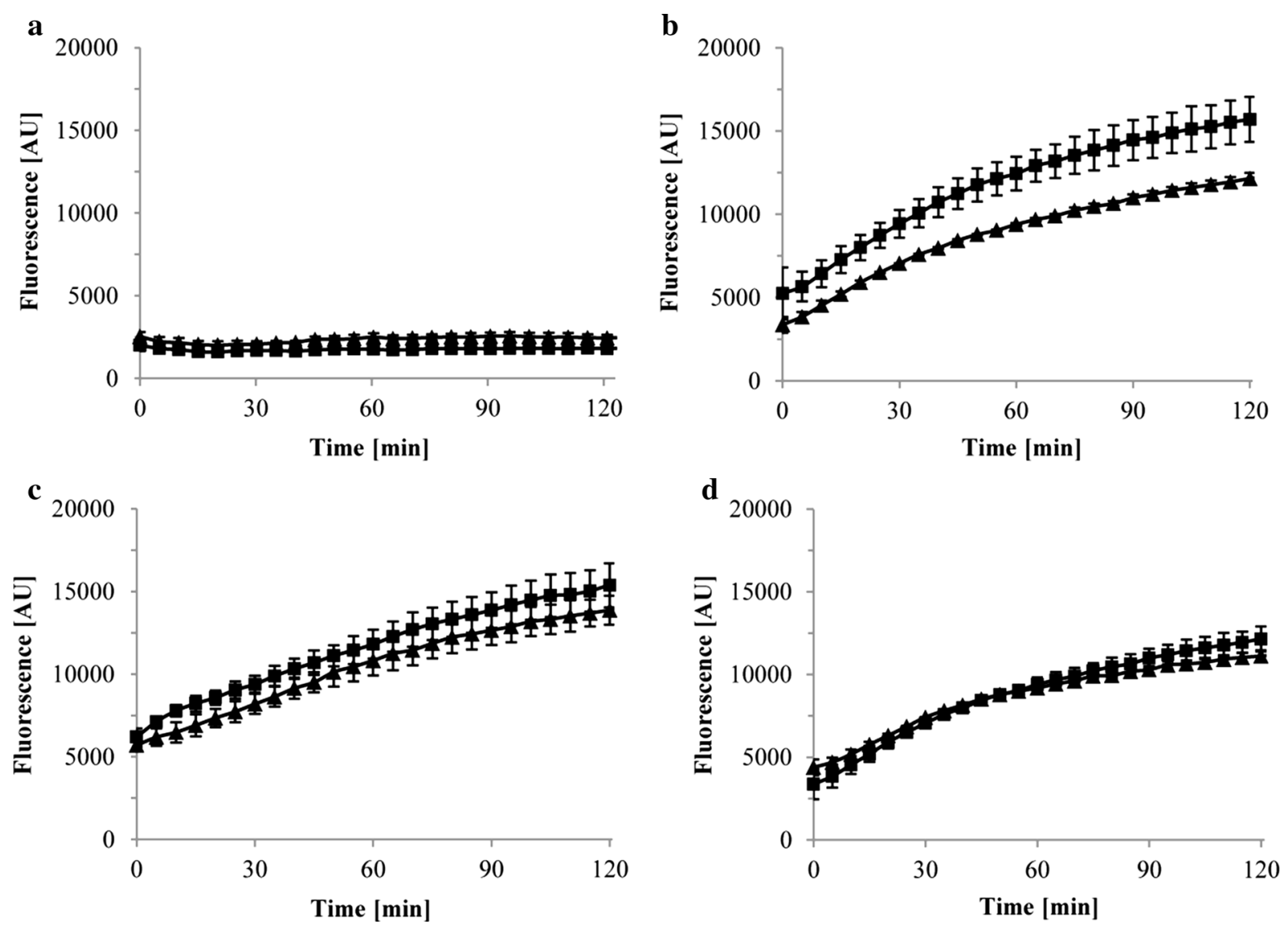

Fig. 4 Influx of Nile Red in cells of $C$. defragrans 65Phen grown on acetate $(10 \mathrm{mM})$ in cometabolism with limonene $(3 \mathrm{mM})$ (wild-type: filled triangles, $\triangle a m e A B C D$ : filled squares). Nile Red $(2 \mu \mathrm{M})$ was added directly to the cells (a) or together with $2 \mu \mathrm{M}$ of the proton-gradient uncoupling agent carbonylcyanide $m$-chlorophenylhydrazone (CCCP) (b). The combined effect of CCCP and the RND pump inhibitor phe-arg $\beta$ -

After Nile Red loading, acetate $(50 \mathrm{mM})$ was added to re-energize the cells and fluorescence was recorded. The efflux of Nile Red showed almost identical apparent kinetics in both strains (Fig. 5a). In experiments where no acetate was added similar efflux curves were observed (data not shown), indicating that acetate addition has no effect on Nile Red efflux in $C$. defragrans. The observed decrease in fluorescence may be caused by passive diffusion of Nile Red to the outside of the cells or by reactivation of transporters after the removal of CCCP during the intermediate washing steps. The obligate-respiring $C$. defragrans reenergizes slowly with acetate in comparison to fermenting bacteria. The latter restore active dye efflux within seconds after glucose addition (Blair and

naphthylamide $(\mathrm{PA} \beta \mathrm{N}, 38.5 \mu \mathrm{M})$ is also shown (c). Cells grown on acetate as only carbon and energy source were also treated with CCCP and tested for Nile Red accumulation (d). The influx of Nile Red was followed by measuring fluorescence intensity (excitation $552 \mathrm{~nm}$, emission $636 \mathrm{~nm}$ ). The error bars indicate the standard deviation of the means for at least three independent experiments

Piddock 2016; Bohnert et al. 2011; Iyer et al. 2015). We used the addition of PA $\beta \mathrm{N}$ to wild-type and $\triangle a m e A B C D$ cells to assess the involvement of active exporters on the efflux process. Here, the extrusion of Nile Red was reduced in both strains (Fig. 5b), suggesting at least a partial contribution of RND pumps in this process.

In silico analysis of RND efflux transporters in $C$. defragrans

The genome of $C$. defragrans contains nine putative RND pumps. Seven of them (NCBI Acc. Numbers CDM22941, CDM23198, CDM23199, CDM24125, CDM24282, CDM24412 and CDM25333) affiliate to 


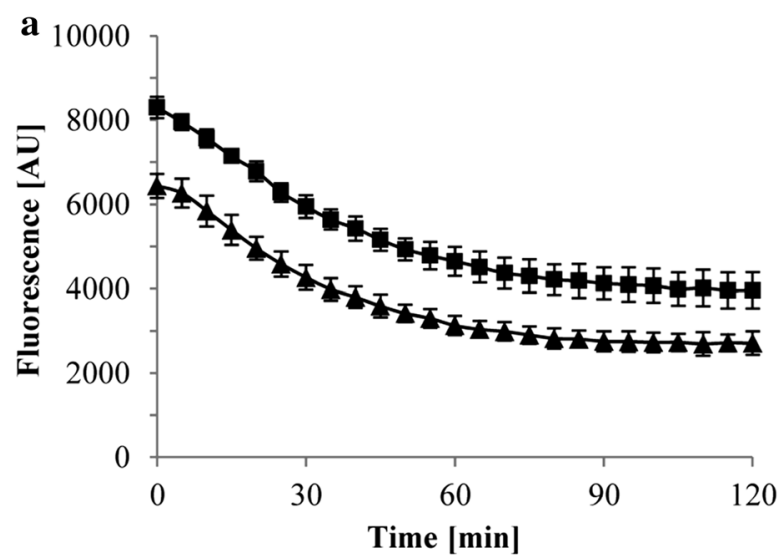

Fig. 5 Nile Red efflux by wild-type (filled triangles) and $\triangle a m e A B C D$ (filled squares) strains of $C$. defragrans 65Phen. Bacterial cells were preloaded with $2 \mu \mathrm{M}$ Nile Red in the presence of $\mathrm{CCCP}(2 \mu \mathrm{M})$ at $28^{\circ} \mathrm{C}$ under constant shaking $(120 \mathrm{rpm})$ for $2 \mathrm{~h}$. After two washing steps, the cells were

the HAE1 family, the most studied group of RND transporters. HAE1 transporters associate with periplasmic and outer membrane proteins and mostly confer tolerance to xenobiotics in clinical and environmental isolates (Blanco et al. 2016; Tseng et al. 1999).

Another transporter (CDM25549) belongs to the SecDF family, a group of chaperon transporters involved in the export of proteins across the inner membrane (Tsukazaki and Nureki 2011). The ninth protein, AmeD (CDM25262), affiliates with the HAE3 family, a family of mainly uncharacterized transporters.

AmeD along with AmeABC were up-regulated in the proteome of $\alpha$-phellandrene-grown $C$. defragrans (Petasch et al. 2014). The closest homologs for the cluster AmeABCD were the hypothetical proteins EPZ15054, EPZ15055, EPZ15056 and EPZ15057 from Thauera terpenica $58 \mathrm{Eu}^{\mathrm{T}}$ with sequence identities ranging between 61 and $80 \%$. Similar to $C$. defragrans, T. terpenica $58 \mathrm{Eu}^{\mathrm{T}}$ is able to anaerobically mineralize a wide range of monocyclic and bicyclic monoterpenes (Foss and Harder 1998).

AmeA (CDM25259) is a protein of 605 amino acid residues. It consists of an $\mathrm{N}$-terminal signal peptide and a large conserved domain of unknown function (DUF1302). Its predicted localization as an outer membrane protein concurs with its inferred structural homology with the outer membrane protein OpcA (PDB: 2VDF) from Neisseria meningitidis (Cherezov

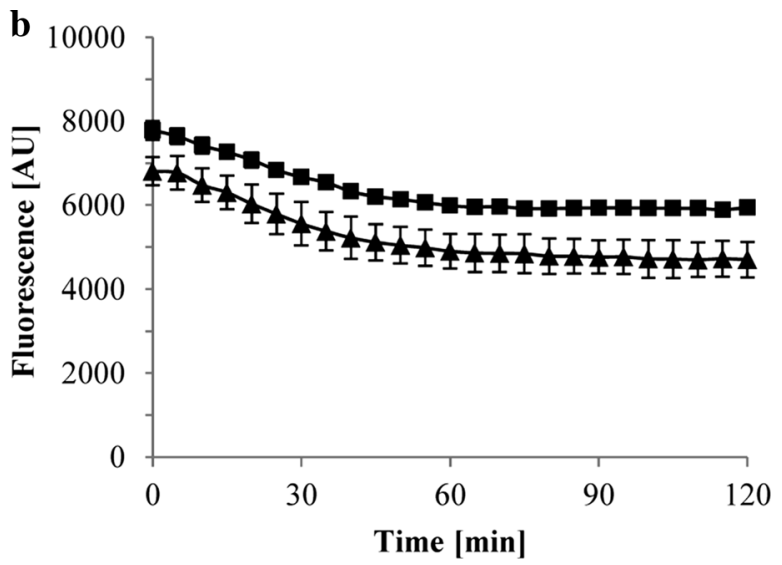

reenergized with $50 \mathrm{mM}$ acetate and fluorescence was recorded (a). The effect of $38.5 \mu \mathrm{M}$ of PA $\beta \mathrm{N}$ on reenergized cells was tested (b). The error bars indicate the standard deviation of the means for at least three independent experiments

et al. 2008; Moore et al. 2005). The second upregulated protein-AmeB (CDM25260, 451 aa)—was predicted as periplasmic and affiliated to the LolA superfamily (DUF1329). Although the crystal structure of several proteins within this superfamily have been resolved (e.g. PDB: 4Z48, 3BK5 and 3BUU), for most their function in the periplasm remains unknown. Protein AmeB has been shown to be essential for growth on monoterpenes since a transposon insertion within $a m e B$ resulted in reduced growth on limonene, myrcene and perillic acid (Petasch et al. 2014). Protein AmeC (CDM25261, 316 aa) affiliates to the COG4447, a group of proteins related to stability and assembly factors of the photosystem II in plants. AmeC is also predicted as a periplasmic protein and hence is likely involved in the assembly of the RND transporter complex. Lastly, protein AmeD (CDM25262, 787 aa) belongs to the RND efflux transporter superfamily and affiliates with the hydrophobe/amphiphile efflux-3 family (HAE3) (COG1033). The 12 transmembrane-spanning (TMS) regions and two periplasmic loops (located between TMS 1 and 2 and between TMS 7 and 8) conserved among all RND efflux pumps were predicted from the amino acid sequence (Fig. S3) (Paulsen et al. 1996; Tseng et al. 1999). In a phylogenetic reconstruction with sequences from the RND transporter families HAE1, HAE2 and HAE3, AmeD and its closest homologs clustered in a distinct lineage within the HAE3 branch (Fig. 6). To date, the only characterized 


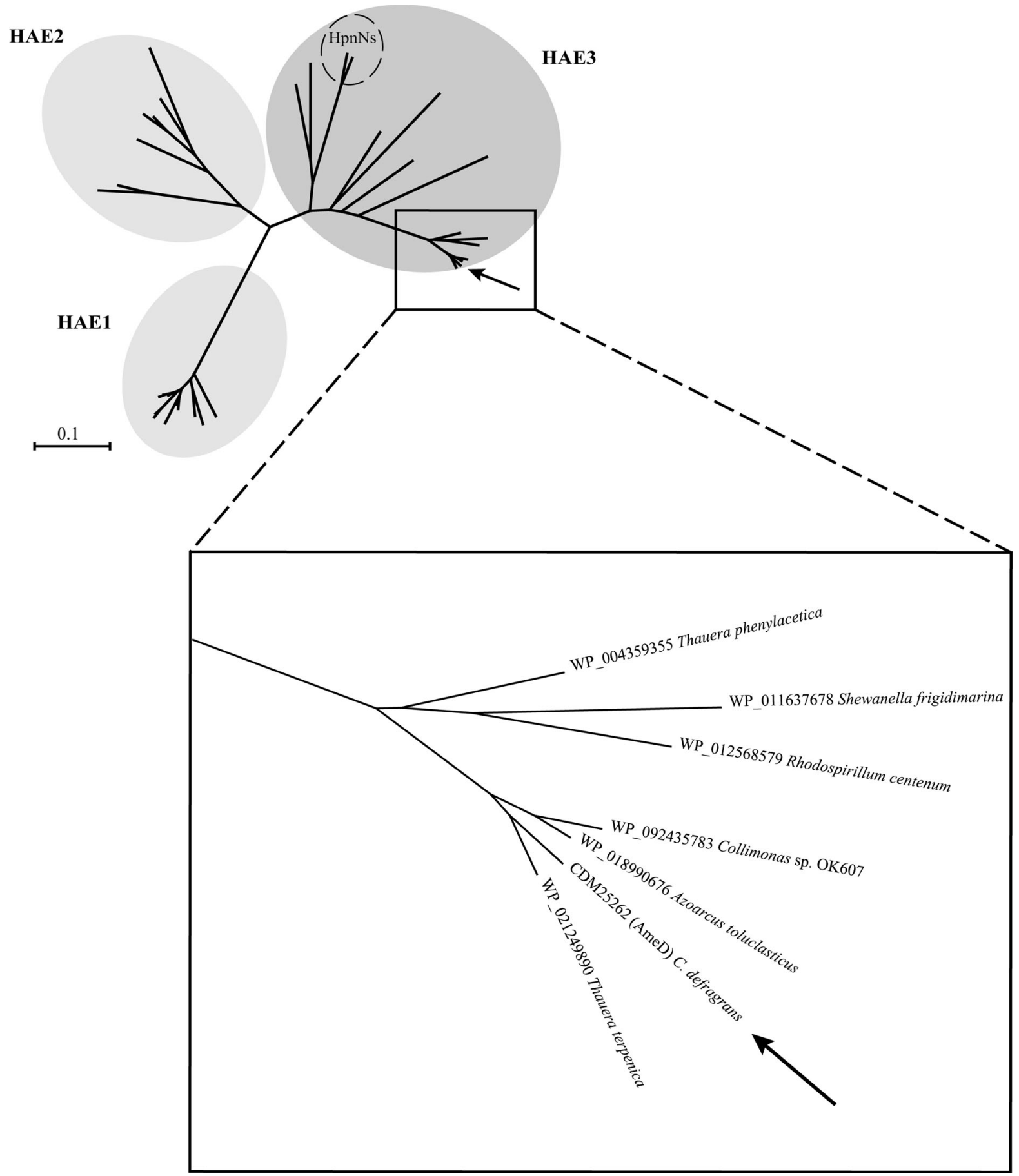

Fig. 6 Unrooted phylogenetic tree of representatives from the RND families HAE1, HAE2 and HAE3. AmeD (arrow) and its closest homologs clustered in a distinct branch within HAE3 (square). RND hopanoid transporters $(\mathrm{HpnN})$ from Rhodopseudomonas palustris TIE-1 and Burkholderia multivorans are indicated within the dashed circle. Enlarged area displays the sequences most closely related to AmeD within the HAE3 family. Proteins sequences of each HAE family were aligned using MAFFT (Katoh et al. 2017). A maximum likelihood tree was calculated with MEGA 7 (Kumar et al. 2016) and visualized with Archaeopteryx 0.9921 beta (Han and Zmasek 2009) 


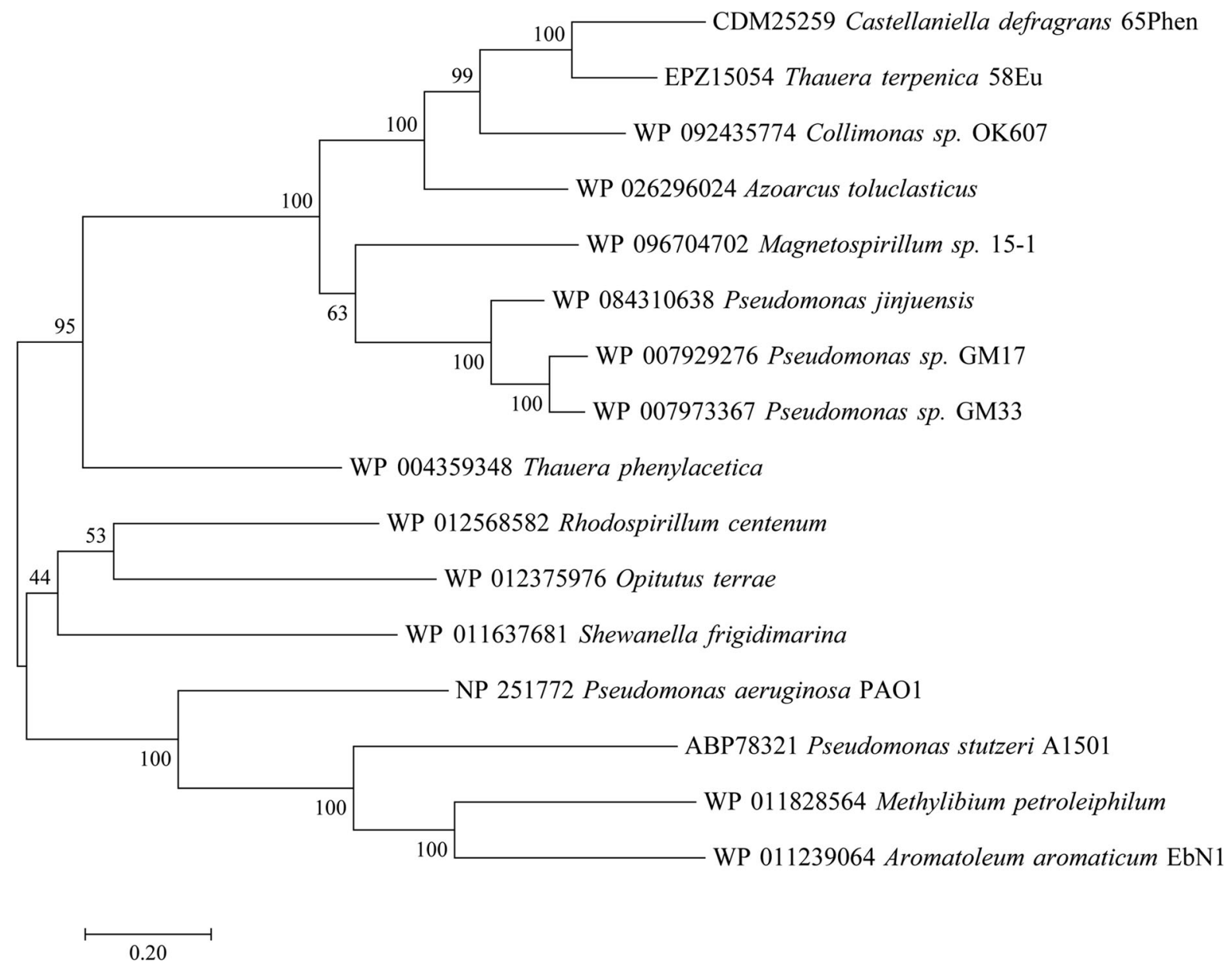

Fig. 7 Unrooted maximum likelihood tree based on JTT matrix-based model inferred from concatenated protein sequence alignments with homology to $C$. defragrans AmeABCD. Gene cassettes were identified and downloaded from RAST (Overbeek et al. 2014), NCBI and UniProt.

representatives from HAE3 are two closely related hopanoid transporters $(\mathrm{HpnN})$ from Rhodopseudomonas palustris TIE-1 and Burkholderia multivorans (Doughty et al. 2011; Kumar et al. 2017). In these two oth organisms, HpnN catalyzes the translocation of hopanoids from the inner membrane to the periplasm without the need for association or cotranscription with periplasmic proteins or outer membrane channels. In contrast, all members in the AmeD lineage are encoded within gene cassettes composed of outer- and inner-membrane proteins homologous to AmeA and AmeD, respectively, and two periplasmic proteins homologous to AmeB and AmeC. Both the composition and the organization of such gene
Homologous proteins from each cassette were clustered and aligned using MAFFT (Katoh et al. 2017). The alignments were concatenated and used for calculating a maximum likelihood tree with MEGA 7 (Kumar et al. 2016). The tree was visualized with Archaeopteryx 0.9921 beta (Han and Zmasek 2009)

cassettes are conserved among the members of this lineage, sharing a close overall phylogenetic history (Fig. 7), and likely representing a new subfamily within HAE3. Intriguingly, this subunit composition and architecture resembles that of RND transporters of the HAE1 family described in numerous Gramnegative bacteria (Daury et al. 2016). Although most HAE1 transporter complexes are composed of three proteins, a few examples for the requirement of a fourth protein are known. The transporter systems CusCFBA and TriABC-OpmH both require two periplasmic proteins to catalyze the efflux of heavy metals (i.e. $\mathrm{Cu}^{+}$and $\mathrm{Ag}^{+}$) and the antimicrobial triclosan, respectively (Delmar et al. 2014; Mima et al. 
2007). Additional efflux systems such as the Mux$\mathrm{ABC}-\mathrm{OpmB}$ and AcrABZ-TolC also require a forth protein which locates in the inner membrane and in the cytoplasm, respectively (Mima et al. 2009; Wang et al. 2017). In our case, the roles of AmeB and AmeC cannot be predicted unequivocally and their definition await for the construction and experimentation with corresponding in-frame, non-polar deletion mutants. Nonetheless, the affiliation of both proteins with periplasmic chaperons suggests their participation in the assembly and stability of the RND complex and hence both may act as MFPs.

\section{Conclusion}

In this study, the role of the putative RND transporter complex AmeABCD in monoterpene growth of $C$. defragrans was investigated. The results showed reduced biomass yield in an ameABCD deletion mutant growing on non-functionalized monoterpenes as sole carbon sources. The addition of acetate as cometabolic substrate increased significantly the tolerance of the deletion mutant towards limonene. Deletion of ameABCD resulted also in higher net influx of Nile Red into CCCP-treated $C$. defragrans, suggesting the participation of the RND transporter in dye efflux in the wild-type cells. AmeD is affiliated to a lineage of RND transporters within the HAE3 family that unlike other HAE3 members associate with two periplasmic proteins and one outer membrane channel analogous to some RND transporter systems of the HAE1 family. It is suggested that AmeB and AmeC act both as periplasmic MFPs. Their homology to chaperones and assembly factors grant both proteins with potential for facilitating protein-protein interactions and hence the assembly of the RND complex. The inducible proteins AmeABCD provide $C$. defragrans with tolerance against the toxic monoterpenes that it naturally uses as carbon and energy sources.

Acknowledgements Open access funding provided by Max Planck Society. We thank Jan Petasch for the construction of the deletion mutant. E.P.C. was supported by a Grant from the DAAD in Germany and by the Corporación para la Investigación de la Corrosión and COLCIENCIAS in Colombia. This study was funded by the Max Planck Society.

\section{Compliance with ethical standards}

Conflict of interest The authors declare that they have no conflict of interest.

Open Access This article is distributed under the terms of the Creative Commons Attribution 4.0 International License (http:// creativecommons.org/licenses/by/4.0/), which permits unrestricted use, distribution, and reproduction in any medium, provided you give appropriate credit to the original author(s) and the source, provide a link to the Creative Commons license, and indicate if changes were made.

\section{References}

Abrahim D, Francischini AC, Pergo EM, Kelmer-Bracht AM, Ishii-Iwamoto EL (2003) Effects of $\alpha$-pinene on the mitochondrial respiration of maize seedlings. Plant Physiol Biochem 41:985-991. https://doi.org/10.1016/j.plaphy. 2003.07.003

Altschul SF, Gish W, Miller W, Myers EW, Lipman DJ (1990) Basic local alignment search tool. J Mol Biol 215:403-410. https://doi.org/10.1016/s0022-2836(05)80360-2

Bicas JL, Fontanille P, Pastore GM, Larroche C (2008) Characterization of monoterpene biotransformation in two pseudomonads. J Appl Microbiol 105:1991-2001. https:// doi.org/10.1111/j.1365-2672.2008.03923.x

Blair JMA, Piddock LJV (2016) How to measure export via bacterial multidrug resistance efflux pumps. mBio 7:e00840-16. https://doi.org/10.1128/mBio.00840-16

Blanco P, Hernando-Amado S, Reales-Calderon JA, Corona F, Lira F, Alcalde-Rico M, Bernardini A, Sanchez MB, Martinez JL (2016) Bacterial multidrug efflux pumps: much more than antibiotic resistance determinants. Microorganisms 4:E14. https://doi.org/10.3390/ microorganisms 4010014

Bohnert JA, Karamian B, Nikaido H (2010) Optimized Nile Red efflux assay of AcrAB-TolC multidrug efflux system shows competition between substrates. Antimicrob Agents Chemother 54:3770-3775. https://doi.org/10.1128/AAC. 00620-10

Bohnert JA, Schuster S, Szymaniak-Vits M, Kern WV (2011) Determination of real-time efflux phenotypes in Escherichia coli AcrB binding pocket phenylalanine mutants using a 1,2'-dinaphthylamine efflux assay. PLoS ONE 6:e21196. https://doi.org/10.1371/journal.pone.0021196

Brennan TCR, Turner CD, Kromer JO, Nielsen LK (2012) Alleviating monoterpene toxicity using a two-phase extractive fermentation for the bioproduction of jet fuel mixtures in Saccharomyces cerevisiae. Biotechnol Bioeng 109:2513-2522. https://doi.org/10.1002/bit.24536

Cherezov V, Liu W, Derrick JP, Luan B, Aksimentiev A, Katritch V, Caffrey M (2008) In meso crystal structure and docking simulations suggest an alternative proteoglycan binding site in the OpcA outer membrane adhesin. Proteins 71:24-34. https://doi.org/10.1002/prot.21841 
Daury L, Orange F, Taveau JC, Verchère A, Monlezun L, Gounou C, Marreddy RK, Picard M, Broutin I, Pos KM, Lambert O (2016) Tripartite assembly of RND multidrug efflux pumps. Nat Commun 7:10731. https://doi.org/10. 1038/ncomms 10731

Delmar JA, Su CC, Yu EW (2014) Bacterial multidrug efflux transporters. Annu Rev Biophys 43:93-117. https://doi. org/10.1146/annurev-biophys-051013-022855

Doughty DM, Coleman ML, Hunter RC, Sessions AL, Summons RE, Newman DK (2011) The RND-family transporter, HpnN, is required for hopanoid localization to the outer membrane of Rhodopseudomonas palustris TIE-1. Proc Natl Acad Sci USA 108:E1045-E1051. https://doi. org/10.1073/pnas.1104209108

Dunlop MJ, Dossani ZY, Szmidt HL, Chu HC, Lee TS, Keasling JD, Hadi MZ, Mukhopadhyay A (2011) Engineering microbial biofuel tolerance and export using efflux pumps. Mol Syst Biol 7:487. https://doi.org/10.1038/Msb.2011.21

Eswaran J, Koronakis E, Higgins MK, Hughes C, Koronakis V (2004) Three's company: component structures bring a closer view of tripartite drug efflux pumps. Curr Opin Struct Biol 14:741-747. https://doi.org/10.1016/j.sbi.2004. 10.003

Finn RD, Attwood TK, Babbitt PC, Bateman A, Bork P, Bridge AJ, Chang HY, Dosztányi Z, El-Gebali S, Fraser M, Gough J, Haft D, Holliday GL, Huang H, Huang X, Letunic I, Lopez R, Lu S, Marchler-Bauer A, Mi H, Mistry J, Natale DA, Necci M, Nuka G, Orengo CA, Park Y, Pesseat S, Piovesan D, Potter SC, Rawlings ND, Redaschi N, Richardson L, Rivoire C, Sangrador-Vegas A, Sigrist C, Sillitoe I, Smithers B, Squizzato S, Sutton G, Thanki N, Thomas PD, Tosatto SC, Wu CH, Xenarios I, Yeh LS, Young SY, Mitchell AL (2017) InterPro in 2017-beyond protein family and domain annotations. Nucleic Acids Res 45:D190-D199. https://doi.org/10.1093/nar/gkw1107

Foo JL, Leong SS (2013) Directed evolution of an E. coli inner membrane transporter for improved efflux of biofuel molecules. Biotechnol Biofuels 6:81. https://doi.org/10. 1186/1754-6834-6-81

Foss S, Harder J (1998) Thauera linaloolentis sp. nov. and Thauera terpenica sp. nov., isolated on oxygen-containing monoterpenes (linalool, menthol, and eucalyptol) and nitrate. Syst Appl Microbiol 21:365-373. https://doi.org/ 10.1016/s0723-2020(98)80046-5

Foss S, Heyen U, Harder J (1998) Alcaligenes defragrans sp. nov., description of four strains isolated on alkenoic monoterpenes $((+)$-menthene, alpha-pinene, 2-carene, and alpha-phellandrene) and nitrate. Syst Appl Microbiol 21:237-244. https:// doi.org/10.1016/s0723-2020(98)80028-3

Garcia V, Godoy P, Daniels C, Hurtado A, Ramos JL, Segura A (2010) Functional analysis of new transporters involved in stress tolerance in Pseudomonas putida DOT-T1E. Environ Microbiol Rep 2:389-395. https://doi.org/10.1111/j. 1758-2229.2009.00093.x

Griffin S, Wyllie SG, Markham J (1999) Determination of octanol-water partition coefficient for terpenoids using reversed-phase high-performance liquid chromatography. J Chromatogr A 864:221-228

Han MV, Zmasek CM (2009) phyloXML: XML for evolutionary biology and comparative genomics. BMC Bioinform 10:356. https://doi.org/10.1186/1471-2105-10-356
Harder J, Marmulla R (2017) Catabolic pathways and enzymes involved in the anaerobic degradation of terpenes. In: Boll M (ed) Anaerobic utilization of hydrocarbons, oils and lipids. Springer, Cham, p 1-15. https://doi.org/10.1007/ 978-3-319-33598-8_8-1

Heyen U (1999) Der anaerobe Abbau von Monoterpenen durch das Betaproteobakterium Alcaligenes defragrans. Dissertation, University Bremen

Iyer R, Ferrari A, Rijnbrand R, Erwin AL (2015) A fluorescent microplate assay quantifies bacterial efflux and demonstrates two distinct compound binding sites in AcrB. Antimicrob Agents Chemother 59:2388-2397. https://doi. org/10.1128/AAC.05112-14

Katoh K, Rozewicki J, Yamada KD (2017) MAFFT online service: multiple sequence alignment, interactive sequence choice and visualization. Brief Bioinform. https://doi.org/ 10.1093/bib/bbx108

Kelley LA, Mezulis S, Yates CM, Wass MN, Sternberg MJ (2015) The Phyre2 web portal for protein modeling, prediction and analysis. Nat Protoc 10:845-858. https://doi. org/10.1038/nprot.2015.053

Kieboom J, Dennis JJ, de Bont JA, Zylstra GJ (1998) Identification and molecular characterization of an efflux pump involved in Pseudomonas putida S12 solvent tolerance. J Biol Chem 273:85-91

Krogh A, Larsson B, von Heijne G, Sonnhammer EL (2001) Predicting transmembrane protein topology with a hidden Markov model: application to complete genomes. J Mol Biol 305:567-580. https://doi.org/10.1006/jmbi.2000. 4315

Kumar S, Stecher G, Tamura K (2016) MEGA7: molecular evolutionary genetics analysis version 7.0 for bigger datasets. Mol Biol Evol 33:1870-1874. https://doi.org/10. 1093/molbev/msw054

Kumar N, Su CC, Chou TH, Radhakrishnan A, Delmar JA, Rajashankar KR, Yu EW (2017) Crystal structures of the Burkholderia multivorans hopanoid transporter HpnN. Proc Natl Acad Sci USA 114:6557-6562. https://doi.org/ 10.1073/pnas.1619660114

Lüddeke F, Dikfidan A, Harder J (2012) Physiology of deletion mutants in the anaerobic $\beta$-myrcene degradation pathway in Castellaniella defragrans. BMC Microbiol 12:192. https://doi.org/10.1186/1471-2180-12-192

Mahmoud SS, Croteau RB (2002) Strategies for transgenic manipulation of monoterpene biosynthesis in plants. Trends Plant Sci 7:366-373

Marchler-Bauer A, Bo Y, Han L, He J, Lanczycki CJ, Lu S, Chitsaz F, Derbyshire MK, Geer RC, Gonzales NR, Gwadz M, Hurwitz DI, Lu F, Marchler GH, Song JS, Thanki N, Wang Z, Yamashita RA, Zhang D, Zheng C, Geer LY, Bryant SH (2017) CDD/SPARCLE: functional classification of proteins via subfamily domain architectures. Nucleic Acids Res 45:D200-D203. https://doi.org/10. 1093/nar/gkw1129

Mima T, Joshi S, Gomez-Escalada M, Schweizer HP (2007) Identification and characterization of TriABC-OpmH, a triclosan efflux pump of Pseudomonas aeruginosa requiring two membrane fusion proteins. $\mathrm{J}$ Bacteriol 189:7600-7609. https://doi.org/10.1128/JB.00850-07

Mima T, Kohira N, Li Y, Sekiya H, Ogawa W, Kuroda T, Tsuchiya T (2009) Gene cloning and characteristics of the 
RND-type multidrug efflux pump MuxABC-OpmB possessing two RND components in Pseudomonas aeruginosa. Microbiology 155:3509-3517. https://doi.org/10. 1099/mic.0.031260-0

Moore J, Bailey SES, Benmechernene Z, Tzitzilonis C, Griffiths NJE, Virji M, Derrick JP (2005) Recognition of saccharides by the OpcA, OpaD, and OpaB outer membrane proteins from Neisseria meningitidis. J Biol Chem 280:31489-31497. https://doi.org/10.1074/jbc.M506354200

Morita Y, Komori Y, Mima T, Kuroda T, Mizushima T, Tsuchiya T (2001) Construction of a series of mutants lacking all of the four major mex operons for multidrug efflux pumps or possessing each one of the operons from Pseudomonas aeruginosa PAO1: MexCD-OprJ is an inducible pump. FEMS Microbiol Lett 202:139-143. https://doi.org/ 10.1111/j.1574-6968.2001.tb10794.x

Nielsen H (2017) Predicting secretory proteins with SignalP. Methods Mol Biol 1611:59-73. https://doi.org/10.1007/ 978-1-4939-7015-5_6

Nikaido H (2011) Structure and mechanism of RND-type multidrug efflux pumps. Adv Enzymol Relat Areas Mol Biol 77:1-60

Overbeek R, Olson R, Pusch GD, Olsen GJ, Davis JJ, Disz T, Edwards RA, Gerdes S, Parrello B, Shukla M, Vonstein V, Wattam AR, Xia F, Stevens R (2014) The SEED and the Rapid Annotation of microbial genomes using Subsystems Technology (RAST). Nucleic Acids Res 42:D206-D214. https://doi.org/10.1093/nar/gkt1226

Paixao L, Rodrigues L, Couto I, Martins M, Fernandes P, de Carvalho CC, Monteiro GA, Sansonetty F, Amaral L, Viveiros M (2009) Fluorometric determination of ethidium bromide efflux kinetics in Escherichia coli. J Biol Eng 3:18. https://doi.org/10.1186/1754-1611-3-18

Papadopoulos CJ, Carson CF, Chang BJ, Riley TV (2008) Role of the MexAB-OprM efflux pump of Pseudomonas aeruginosa in tolerance to tea tree (Melaleuca altenifolia) oil and its monoterpene components terpinen-4-ol, 1,8-cineole, and $\alpha$-terpineol. Appl Environ Microbiol 74:1932-1935. https://doi.org/10.1128/Aem.02334-07

Paulsen IT, Brown MH, Skurray RA (1996) Proton-dependent multidrug efflux systems. Microbiol Rev 60:575-608

Petasch J, Disch EM, Markert S, Becher D, Schweder T, Hüttel B, Reinhardt R, Harder J (2014) The oxygen-independent metabolism of cyclic monoterpenes in Castellaniella defragrans 65Phen. BMC Microbiol 14:164. https://doi. org/10.1186/1471-2180-14-164

Ramos JL, Duque E, Gallegos MT, Godoy P, Ramos-Gonzalez MI, Rojas A, Teran W, Segura A (2002) Mechanisms of solvent tolerance in Gram-negative bacteria. Annu Rev Microbiol 56:743-768. https://doi.org/10.1146/annurev. micro.56.012302.161038

Richmond GE, Chua KL, Piddock LJV (2013) Efflux in Acinetobacter baumannii can be determined by measuring accumulation of H33342 (bis-benzamide). J Antimicrob Chemother 68:1594-1600. https://doi.org/10.1093/jac/ dkt052

Saier MH Jr, Reddy VS, Tsu BV, Ahmed MS, Li C, MorenoHagelsieb G (2016) The Transporter Classification Database (TCDB): recent advances. Nucleic Acids Res 44:D372-D379. https://doi.org/10.1093/nar/gkv1103

Segura A, Molina L, Fillet S, Krell T, Bernal P, Munoz-Rojas J, Ramos JL (2012) Solvent tolerance in Gram-negative bacteria. Curr Opin Biotechnol 23:415-421. https://doi. org/10.1016/j.copbio.2011.11.015

Sikkema J, Debont JAM, Poolman B (1995) Mechanisms of membrane toxicity of hydrocarbons. Microbiol Rev 59:201-222

Sonnhammer EL, von Heijne G, Krogh A (1998) A hidden Markov model for predicting transmembrane helices in protein sequences. Proc Int Conf Intell Syst Mol Biol $6: 175-182$

Soto SM (2013) Role of efflux pumps in the antibiotic resistance of bacteria embedded in a biofilm. Virulence 4:223-229. https://doi.org/10.4161/viru.23724

Spyropoulos IC, Liakopoulos TD, Bagos PG, Hamodrakas SJ (2004) TMRPres2D: high quality visual representation of transmembrane protein models. Bioinformatics 20:32583260. https://doi.org/10.1093/bioinformatics/bth358

Tseng TT, Gratwick KS, Kollman J, Park D, Nies DH, Goffeau A, Saier MH Jr (1999) The RND permease superfamily: an ancient, ubiquitous and diverse family that includes human disease and development proteins. J Mol Microbiol Biotechnol 1:107-125

Tsukazaki T, Nureki O (2011) The mechanism of protein export enhancement by the SecDF membrane component. Biophysics 7:129-133. https://doi.org/10.2142/biophysics.7. 129

Ultee A, Kets EPW, Alberda M, Hoekstra FA, Smid EJ (2000) Adaptation of the food-borne pathogen Bacillus cereus to carvacrol. Arch Microbiol 174:233-238. https://doi.org/ 10.1007/s002030000199

Uribe S, Alvarez R, Pena A (1984) Effects of $\beta$-Pinene, a nonsubstituted monoterpene, on rat-liver mitochondria. Pestic Biochem Phys 22:43-50. https://doi.org/10.1016/00483575(84)90008-7

Wang Z, Fan G, Hryc CF, Blaza JN, Serysheva II, Schmid MF, Chiu W, Luisi BF, Du D (2017) An allosteric transport mechanism for the AcrAB-TolC multidrug efflux pump. eLife 6:e24905. https://doi.org/10.7554/eLife.24905

Yu NY et al (2010) PSORTb 3.0: improved protein subcellular localization prediction with refined localization subcategories and predictive capabilities for all prokaryotes. Bioinformatics 26:1608-1615. https://doi.org/10.1093/ bioinformatics/btq249 